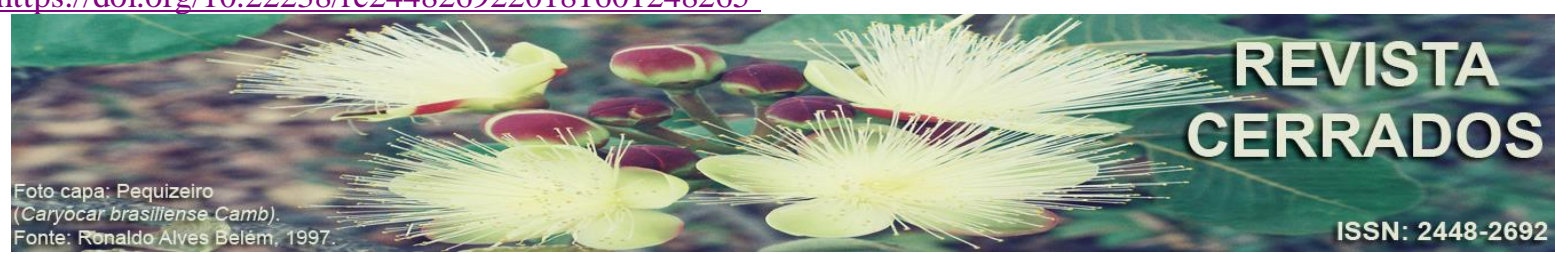

\title{
COMUNIDADES REMANESCENTES DE QUILOMBOS: reflexão sobre territorialidades
}

\section{REMAINING QUILOMBO COMMUNITIES: a reflection on territorialities}

\section{VESTIGIOS DE COMUNIDADES DE QUILOMBO: reflexión sobre territorialidades}

\author{
Lilian Maria Santos (ID) 9 \\ Universidade Estadual de Montes Claros - UNIMONTES \\ E-mail: <lilianmsantos@yahoo.com.br>. \\ Anete Marília Pereira (D) 9 \\ Universidade Estadual de Montes Claros - UNIMONTES \\ E-mail: <anetemarilia@gmail.com>. \\ Andréa Maria Narciso Rocha de Paula \\ Universidade Estadual de Montes Claros - UNIMONTES \\ E-mail: <andreapirapora@yahoo.com.br>.
}

\begin{abstract}
RESUMO
Pretende-se discutir neste artigo o processo de territorialidade para formação das comunidades remanescentes de quilombos no Brasil. E, para tanto, fez-se necessário compreender as diversas concepções sobre a categoria Comunidade Tradicional no que tange a perspectivas classificatórias, políticas, jurídicas e territoriais, bem como aos aspectos envolvidos na constituição das Comunidades Remanescentes de Quilombos. A comunidade tradicional se reconhece pela tradicionalização como estratégia e movimento de luta e resistência em defesa do seu território. O processo de identificação e reconhecimento da comunidade remanescente de quilombo perpassa pela ressemantização do termo "Quilombo" e politização do grupo social na consolidação pelo direito coletivo do território e manutenção do modo de vida. A memória de luta e resistência, as práticas envolvendo a terra, em seu valor de uso para o trabalho e manutenção da cultura, a reciprocidade e as fronteiras simbólicas engendram a territorialidade das comunidades remanescentes de quilombo. São a trajetória da vida cotidiana, as relações estabelecidas pelos sujeitos no lugar - que fazem a sua história - que constroem o processo de territorialidade. O território se constitui, portanto, em uma produção histórica, relacional material e imaterial, e a territorialidade trata da dimensão vivencial e subjetiva, ou seja, do campo experiencial daqueles que vivenciam o processo de territorialização.

Licenciada sob Creative Commons (cc) BY-No-ND


Palavras-chave: Comunidades Tradicionais. Território. Territorialidade. Remanescentes Quilombolas.

\begin{abstract}
This paper aims to discuss the process of territoriality for the formation of the remaining communities of Quilombo in Brazil. It was necessary to understand the different concepts of the traditional community category in terms of qualifying, political, legal and territorial perspectives and the aspects involved in the constitution of the remaining Quilombo communities. The traditional community is recognized by the traditionalization as a strategy, and the struggle and resistance movement in defense of territory. The process of identification and recognition of the remaining Quilombo community traverses by resemantization of Quilombo term and politicization of the social group to consolidate the collective right of the territory and maintaining the way of life. The memory of struggle and resistance, practices involving the land in its use value to the work and for the maintenance of culture, reciprocity and symbolic boundaries engender the territoriality of remnants of Quilombo communities. The trajectory of everyday life, the relationships established by individuals in place-which make their story that builds the process of territoriality. The territory constitutes a historical production, material and immaterial relational and territoriality deals with the existential and subjective dimension, that is, the experiential field of those who experience the process of territorialization.
\end{abstract}

Keywords: Traditional Communities. Territory. Territoriality.Remaining Quilombo.

\title{
RESUMEN
}

Este artículo pretende discutir el proceso de territorialidad para la formación de los vestigios de comunidades de Quilombo en Brasil. Es necesario comprender las diferentes concepciones sobre la categoria "comunidad tradicional" en lo que tiene que ver con las perspectivas clasificatorias, políticas, jurídicas y territoriales, asi como com los aspectos involucrados en la constitución de los vestígios de comunidades quilombolas.La comunidad tradicional es reconocida por la tradicionalización como estrategia y movimiento de lucha y resistencia en defensa del territorio. El proceso de identificación y de reconocimiento de los vestigios de comunidades de Quilombo pasa por la resemantización del termino Quilombo y la politización del grupo social en la consolidación por el derecho colectivo al territorio y a la manutención del modo de vida. La memoria de lucha y resistencia, las prácticas que involucran la tierra y su valor de uso para el trabajo y el manutención de la cultura, la reciprocidad y las fronteras simbólicas engendrar la territorialidad de los vestigios de las comunidades de Quilombo. Son la trayectoria de la vida cotidiana, las relaciones establecidas por los sujetos en el lugar-que hacen su historia - que construyen el proceso de territorialidad. El territorio se constituye como una producción histórica, relacional material e inmaterial y la territorialidad trata de la dimensión existencial y subjetiva, es decir, el campo experiencial de aquellos que vivencian el proceso de territorialización.

Palabras clave: Comunidades tradicionales. El território. La territorialidade. Vestígios de Quilombo. 


\section{INTRODUÇÃO}

Este artigo tem como propósito discutir sobre a formação das comunidades de Remanescentes dos Quilombos no Brasil. De forma especial e dando maior destaque à Comunidade de Remanescentes Quilombolas de Palmeirinha - situada no Município de Pedras de Maria da Cruz, Região Norte de Minas Gerais - no que tange ao processo de territorialidade dessa enquanto Comunidade Tradicional. A discussão aqui proposta é oriunda da necessidade de se avançar no estudo sobre o processo de territorialidade na formação das Comunidades de Remanescentes dos Quilombos, pois esta temática remete à história da colonização brasileira e às suas práticas de dominação, exclusão e violência que marcaram historiografia dessas populações. Nesse contexto a territorialidade é questão central na luta pela terra - considerando a apropriação cultural, memorial e religiosa - e pelo protagonismo social dos Quilombolas.

As Comunidades de Remanescentes dos Quilombos são caracterizadas como Comunidades Tradicionais não somente pela questão legal Brasileira, mas também por perpassar uma perspectiva epistemológica. Na concepção de Diegues (2001), ao tratarmos sobre comunidades tradicionais, devemos partir do princípio de que existe uma relação homem-natureza, na qual estão implícitas as práticas culturais. Para tanto o autor lista onze indicadores que caracterizam as comunidades tradicionais, ressaltando que nenhum deles pode ser tomado de forma isolada, mas destaca que o mais relevante é "reconhecer se pertencente àquele grupo social” (DIEGUES, 2001, p. 86), pois é este critério que remete à condição de sentimento de pertencimento, de identificação e de constituição da identidade.

Enquanto Diegues (2001) centra sua idéia na relação homem-natureza, Little (2002), com o intuito de esclarecer sobre o conceito de Povos Tradicionais, centra-se na questão territorial. Esse autor, assim, informa que sua opção "pela palavra 'povos' - em vez de grupos, comunidades, sociedades ou populações - coloca esse conceito dentro dos debates sobre os direitos dos povos, onde se transforma num instrumento estratégico nas lutas por justiça social desses povos" (LITTLE, 2002, p.23), e apresenta a dimensão empírica e política como “quase inseparáveis" (LITTLE, 2002,p. 22).

Com uma análise mais prospectiva e, em alguns aspectos, discordante da perspectiva classificatória de Diegues, Brandão (2012) retoma teóricos da Antropologia Clássica e se debruça a discutir e sistematizar uma concepção de Comunidade Tradicional, em 
que se propõe a rever paradigmas e compreender o que existe entre a sociedade indígena e a sociedade moderna urbana. Orientado pelos estudos de Éric Wolf, o autor explica que a formação de uma sociedade indígena é anterior ao mundo das cidades e "se reproduzem sem elas" (BRANDÃO, 2012, p. 347), ou seja, sua existência se dá e se desenvolve fora da lógica da cidade, enquanto que as comunidades tradicionais vivem em função da organização da vida urbana. De acordo com Brandão, as comunidades tradicionais são o que o "antropólogo encontra quando sai da floresta, da tribo, da aldeia indígena" (BRANDÃO, 2012, p.347). A comunidade tradicional surge a partir das sociedades modernas, elas se organizam a partir de, e em função de.

Podemos considerar que a categorização de comunidades tradicionais nem sempre é assentada pelos autores no mesmo campo teórico. Os conceitos circulam por dimensões culturais, jurídicas, empíricas, políticas e vivenciais. Porém, todos autores citados aqui convergem ao mesmo ponto ao conceberem as comunidades remanescentes dos quilombos como tradicionais. Nesse contexto um ponto crucial de convergência é a territorialidade, ou seja, a identidade, o sentimento de pertencimento ao lugar. A territorialidade diz da vivência humana na experiência cotidiana de relações, de trabalho, do ir e vir, é o conjunto de relações estabelecidas pela sociedade. De acordo com Raffestin (1993) e Saquet (2007), a territorialidade envolve os processos dinâmicos de todas as instâncias humanas refletidas no cotidiano do território. Para Haesbaert (2004) território remete à noção de dominação da terra em uma perspectiva jurídico-política. Nesse sentido a discussão envolve aqueles que podem, efetivamente, se apropriar da terra como também aqueles que são expropriados dela. Para esse autor o território envolve as diversas dimensões de poder, tanto no âmbito simbólico como do valor de uso.

Território, assim, em qualquer acepção, tem a ver com poder, mas não apenas ao tradicional "poder político". Ele diz respeito tanto ao poder no sentido mais concreto, de dominação, quanto ao poder no sentido mais simbólico, de apropriação. (...) enquanto "espaço-tempo vivido", o território é sempre múltiplo, "diverso e complexo", ao contrário do território "unifuncional" proposto pela lógica capitalista hegemônica (HAESBAERT, 2004 p 01-02).

Haesbaert refere-se a Lefebvre para apontar as dimensões processual e social na construção do território, pois essas envolvem a apropriação da natureza e a dominação orientada pela lógica do capital. 


\section{A FORMAÇÃO DOS TERRITÓRIOS E O PROCESSO DE TERRITORIALIDADE DAS COMUNIDADES REMANESCENTES DOS QUILOMBOS}

Os dados que remetem ao início da formação das comunidades Quilombolas no Brasil mostram, com pouca precisão de datas, que os primeiros quilombos foram organizados no primeiro período do Brasil colônia, aproximadamente no final do séc. XVI e início do séc. XVII. Supõe se que o Quilombo dos Palmares tenha sido o primeiro ou um dos primeiros, inclusive foi considerado o mais populoso no séc. XVII. Os quilombos eram formados por grupos de escravos fugitivos e variavam em relação à área que ocupavam, ao isolamento, à distância dos núcleos populacionais e ao número de pessoas que os compunham. Um Quilombo podia ter dezenas, centenas ou milhares de pessoas, como no caso da população do Quilombo dos Palmares (REIS, 1995-96).

As pessoas que compunham um quilombo buscavam um viver livre e distante das terras dos seus senhores e, por isso, alçavam terras desconhecidas, onde remontavam seus modos de vida trazidos de outro continente. Nos quilombos formavam um grupo que tencionava com o sistema escravocrata vigente e desenvolviam novas formas de vida através das práticas culturais africanas, constituindo um novo território que compreendia uma área delimitada e regulada por relações de poder, sendo construído, desconstruído, ocupado e organizado por essa mesma lógica. De acordo com Little (2002) o território surge no processo de ocupação, uso e controle de um determinado ambiente biofísico, por um grupo social, organizado coletivamente, que se vincula e passa a se sentir pertencente daquele ambiente.

O fato de que um território surge diretamente das condutas de territorialidade de um grupo social implica que qualquer território é um produto histórico de processos sociais e políticos. Para analisar o território de qualquer grupo, portanto, precisa-se de uma abordagem histórica que trata do contexto específico em que surgiu e dos contextos em que foi defendido e/ou reafirmado (LITTLE, 2002, p. 03-04).

Segundo Little (2002), vários processos podem alterar as lógicas territoriais, como por exemplo, a miscigenação, etnocídio, entre outros, assim dando lugar à emergência de novas identidades étnicas, como aconteceu com os quilombos. Esses grupos utilizaram por muito tempo a invisibilidade como estratégia de favorecer a sua sobreviência. Os quilombos eram inicialmente chamados pelos donos de escravos de mocambo e, posteriormente, foram denominados de Quilombo. Esta tem sua origem na palavra africana "Kilombo”, remetendo ao idioma "Mbundu", pertencente a uma sociedade de jovens guerreiros. "O próprio termo 
quilombo derivaria de kilombo, uma sociedade iniciática de jovens guerreiros mbundu adotada pelos invasores jaga (ou imbangala), estes formados por gente de vários grupos étnicos desenraizada de suas comunidades" (REIS, 1995-96, p. 16).

Para Reis, assim como para Leite (2000), quilombo é uma reinvenção dos próprios moradores dos quilombos, como uma forma de retomar o significado de gente guerreira e enfrentar o problema de perda das raízes em um movimento de manutenção e resistência. Reis destaca que foram os Palmarinos que consagraram o termo como um lugar de escravos fugitivos. Leite cita KabengeleMunanga que afirma que "o quilombo brasileiro é, sem dúvida, uma cópia do quilombo africano reconstituído pelos escravizados para se opor a uma estrutura escravocrata, pela implantação de uma outra estrutura política na qual se encontravam todos os oprimidos" (KABENGELEMUNANGA, 1995/6: 57-63 apud LEITE, 2000, p. 336), caracterizando assim um processo de reterritorialização. Saquet (2007) referese a Raffestin (1984) para apresentar sua discussão sobre Territorialização, Desterritorialização e Reterritorialização (TDR) e realça que, para esse autor, esses processos se dão principalmente na dinâmica econômica. A Territorialização é o processo de relações sociais e espaciais, de construção e reconstrução da vida cotidiana. A Desterritorialização é produzida a partir das forças econômicas, políticas e culturais. A Reterritorialização, por sua vez, é a reprodução social, cultural, econômica e política da vida anterior.

Para Saquet (2007) os processos de TDR coexistem, porém de forma descontínua, considerando também os aspectos, sociais, políticos e culturais.

O processo de territorialização é um movimento historicamente determinado; é um dos produtos socioespaciais do movimento e das contradições sociais, sob as forças econômicas, políticas e culturais, que determinam as diferentes territorialidades, no tempo e no espaço, as próprias des-territorialidades e as re-territorialidades. Estes processos (des-re-territorialização) são concomitantes, nos quais, a natureza exterior ao homem é um dos componentes importantes (SAQUET, 2007, p. 69).

No processo de re-territorialização os modos de vida anterior são fundantes na construção do território, os fatores históricos e multiescalares determinam a produção imaterial do território. A imaterialidade está presente na materialidade e vice-versa, são as próprias relações sociais que se objetivam e subjetivam, coexistem e estão no nível da abstração (SAQUET, 2007).

Os negros vieram em navios negreiros, trazidos pelos comerciantes que serviam aos colonizadores, vieram de outro continente e abarcaram, trouxeram com eles a memória de 
outro lugar e chegaram para servir a uma organização de sociedade moderna. "Os índios em seu habitat não podiam ser escravizados, mas os africanos que não falavam a língua dos animais da América nem tinham amizade com as plantas, sofriam o chicote, a corrente e o tronco a troco do impiedoso gesto que entregava a rude comida" (MARÉS, 1999, p. 07).

De acordo com as concepções de Brandão (2012) sobre comunidades Tradicionais, podemos conceber que os negros ao formarem os quilombos, estabeleciam ali uma organização comunitária daqueles que fugiam da escravidão e idealizavam um viver livre, mas levavam com eles a memória de onde vieram, como chegaram e porque vieram.

Ali, africanos de diferentes grupos étnicos administraram suas diferenças e forjaram novos laços de solidariedade, recriaram culturas. Apesar da falta de dados mais diretos, considerando a direção do tráfico atlântico na época, supõe-se que Palmares foi predominantemente um cadinho de grupos originários do Centro-Sul da África, gente de grupos lingüísticoskikongo, kimbundu, ovimbundo e outros da região Congo-Angola. (REIS, 1995-96, p. 16).

Em Minas Gerais os quilombos foram sendo formados a partir do sec. XVIII, sobre esse tema Querino (2006) lança mão de estudos que discutem sobre o Quilombo do Campo Grande - que engloba Minas Gerais, Goiás, São Paulo e Rio de Janeiro - e aponta que este era maior e mais populoso do que o Quilombo dos Palmares. Para Querino (2006, p. 12) "Campo Grande e sua rede, habitada inicialmente por negros fugidos abrigou também pretos forros e brancos pobres oprimidos pelo sistema tributário da Capitação".

No que envolve a formação das comunidades afro-brasileiras no Norte de Minas, Querino (2006) procura descrever os quilombos realçando que na região existiam negros fugitivos, negros livres, negros vindos de outros quilombos, brancos pobres ou fugidos das penalizações legais. As áreas ocupadas por essa população não despertavam o interesse dos colonizadores, pois eram consideradas insalubres, assim os negros embrenharam-se pelas matas em busca de sobrevivência e liberdade. Desse modo, o território dos quilombos era produzido a partir da apropriação de terras, nas quais os negros exerciam sua liberdade e reproduziam sua cultura. Essa concepção de território está presente nos estudos de Saquet (2007), quando considera que o processo de produção do território é um movimento constante e contínuo que conjuga "aspectos da economia, da política, da cultura e da natureza exterior ao homem (E-P-C-N)” (SAQUET, 2007,p.56). Este autor compreende o território como um espaço de relações de poder onde acontecem as expressões morais e legais da organização social, das redes de relações sociais, das tensões decorrentes do domínio capitalista, ou seja, o 
território, assim como a territorialidade é uma produção social e histórica. O território não é estático, ele produz e se reproduz conforme se organiza a sociedade em cada momento histórico numa perspectiva dialética, ou seja, o território é dinâmico e fluido.

Costa (1999) chama atenção para a ausência de documentação fidedigna sobre as populações afro-brasileiras na região Norte de Minas, inclusive realça a omissão de algumas comunidades. “A falta de documentação nessa área conduziu Guimarães \& Mendonça (1997) quando do levantamento das comunidades afro-brasileiras em Minas Gerais, a omitir a existência de diversas localidades que regionalmente são conhecidas como de exclusividade negra (...)" (COSTA, 1999, p. 16). Reverbera ainda sobre os escritos de Burton (1977), SaintHilaire (1938) e Wells (1886), que percorreram o Vale do São Francisco e afirmaram que a maioria da população que encontraram em Contendas, Pedras de Maria da Cruz, Brejo do Amparo e Morrinhos era negra.

No que tange à regulamentação das terras dos Quilombolas no Norte de Minas e investigação sobre os modos de vida dessas comunidades, Costa (1999) se dedicou ao estudo do Brejo dos Crioulos - que é formado pelas comunidades de Arapuim, Araruba, Boa Vista, Caxambu I, Caxambu II, Conrado, Furado Modesto, Furado Seco, Lagoa da Varanda, Orion, Serra D'água e Vista Alegre - e oportunizou-nos o conhecimento da formação social desse circuito de comunidades quilombolas, esclarecendo a partir dos registros históricos e da história contada e vivida pelos próprios moradores, como chegaram, viveram e mantiveram sua memória coletiva sobre seus modos de vida. Esse estudo fornece informações que nos ajudam a compreender a formação das comunidades Quilombolas do Norte de Minas, assim como o estudo de Costa Filho (2008) sobre o povo gurutubano em um quilombo no centro norte mineiro, e de Araujo (2009) sobre a Comunidade Quilombola da Lapinha. Trabalhos que nos propiciam entender as práticas sociais, jurídicas, culturais e econômicas dessas comunidades, bem como a sua formação territorial.

Os estudos anteriormente citados, além de remontarem a história social e cultural dessas comunidades, também oportunizam o esclarecimento sobre os movimentos políticos e jurídicos que desembocaram em legislações. Little (2002), ao discorrer sobre os diversos grupos de Populações Tradicionais, confere que "Outro elemento fundamental dos territórios sociais é encontrado nos vínculos sociais, simbólicos e rituais que os diversos grupos sociais diferenciados mantêm com seus respectivos ambientes biofísicos" (LITTLE, 2002, p. 10). Assim, define lugar como essa apropriação subjetiva envolvida no sentimento de 
pertencimento, que atribui valor específico e próprio a tudo que é e diz do território. Nesse propósito, caminha para a constatação de que o percurso de ocupação do território desses grupos sociais fornece um peso histórico que constrói uma memória coletiva, inclusive no que envolve a disputa pelo território, fator marcante na vida das comunidades tradicionais. No que diz respeito à dimensão política é exatamente a constância da luta pelo território que faz com que os povos tradicionais se mobilizem - via movimentos sociais na década de 1960 e 1970 para a elaboração de "novas estratégias territoriais para defender suas áreas. Isto, por sua vez, deu lugar à atual onda de territorializações em curso" (LITTLE, 2002, p. 13) e culminou em legislações que buscam reconhecimento parcial dos territórios tradicionais.

Tais legislações garantem não somente a visibilidade dessas comunidades, que outrora necessitaram de se fazerem invisíveis, bem como os direitos que foram usurpados dessa população durante a história de opressão exercida pela lógica de dominação dos escravocratas, pelos fazendeiros e pelo Estado. Os artigos 68, 215 e 216 da Constituição da República Federativa do Brasil, de 1988, especificam sobre os direitos dos remanescentes dos quilombos e os deveres do Estado com essas populações,

Art. 68. Aos remanescentes das comunidades dos quilombos que estejam ocupando suas terras é reconhecida a propriedade definitiva, devendo o Estado emitir-lhes os títulos respectivos.

Art. 215. O Estado garantirá a todos o pleno exercício dos direitos culturais e acesso às fontes da cultura nacional, e apoiará e incentivará a valorização e a difusão das manifestações culturais. $\S 1^{\circ}$ - O Estado protegerá as manifestações das culturas populares, indígenas e afro-brasileiras, e das de outros grupos participantes do processo civilizatório nacional. $\S 2^{\circ}$ - A lei disporá sobre a fixação de datas comemorativas de alta significação para os diferentes segmentos étnicos nacionais.

Art. 216. Constituem patrimônio cultural brasileiro os bens de natureza material e imaterial, tomados individualmente ou em conjunto, portadores de referência à identidade, à ação, à memória dos diferentes grupos formadores da sociedade brasileira $[\ldots] \S 1^{\circ}$ - O Poder Público, com a colaboração da comunidade, promoverá e protegerá o patrimônio cultural brasileiro, por meio de inventários, registros, vigilância, tombamento e desapropriação, e de outras formas de acautelamento e preservação. (CONSTITUIÇÃO FEDERAL, 1988).

Os estudos citados, além de nos orientar para a compreensão sobre a formação das comunidades no Norte de Minas Gerais, ensejam a inferência de que as 153 comunidades quilombolas (Querino, 2006) existentes na região passaram por processo semelhante de formação, embora nem todas tenham estudos relacionados, como os de Costa, Costa e Filho e Araujo, que apontam as especificidades de sua formação territorial e manutenção da cultura. 
Little (2002) considera que nos grupos ditos como tradicionais (indígenas, quilombolas, caboclos e outros) existem semelhanças relevantes que compõem o percurso histórico, social, cultural e econômico, caracterizando uma mesma categoria. Nessa direção encontra eixos de articulação social e política que se convergem na questão do território que “implica que qualquer território é um produto histórico de processos sociais e políticos" (LITTLE, 2002, p. 03).

Para compreendermos os processos que envolvem as comunidades remanescentes de quilombos temos que considerar que o termo "quilombo" vem sendo ressemantizado, pois, ao invés do reducionismo de uma condição arqueológica, remete-se a grupos que têm como características comuns o modo de vida camponês, o uso comum da terra, uma relação harmônica com a natureza, resistência na manutenção de seus territórios e movimento de politização da identidade no processo de auto-identificação quilombola (COSTA FILHO, 2008; FIGUEIREDO, 2009).

Dentre as várias comunidades remanescentes de quilombos existentes no Norte de Minas, de acordo com Lima (2013), a comunidade de Palmeirinha faz parte de uma rede de três comunidades - Palmeirinha, Jacarezinho e Alto Grande - de remanescentes de quilombos, formada por aproximadamente 778 pessoas parentes e/ou descendentes dos primeiros ocupantes que lá chegaram, há mais ou menos 150 anos. Palmeirinha está localizada na zona rural de Pedras de Maria da Cruz - MG, município que em 2010 possuía 10.315 habitantes (IBGE, 2010).

Ainda são escassos dados e estudos científicos mais específicos, contemplando a história, os modos de vida e a realidade da Comunidade de Palmeirinha. A maior parte dessas informações consta em "blogs" e "sites"1 da internet com o objetivo de apresentar legislações, divulgar e afirmar a cultura negra, bem como os movimentos de luta, resistência pela terra e conquistas das comunidades de remanescentes dos quilombos.

Segundo os sites a ocupação da região de Pedras de Maria da Cruz iniciou-se no século XVIII e tem relação com a família de Matias Cardoso, pois Maria da Cruz era casada com Salvador Cardoso de Oliveira, sobrinho do bandeirante. A família de Maria da Cruz era

\footnotetext{
${ }^{1}$ http://vivaquilombo.blogspot.com.br https://kizoomba.wordpress.com http://www.palmares.gov.br
} 
proprietária de fazendas e escravos e participou do movimento de revolta contra a cobrança elevada de impostos atrasados pela coroa Portuguesa, o que acabou culminando em vários combates na região do médio São Francisco. Esses combates foram lembrados na memória coletiva dos moradores de Palmeirinha como revoltosos. Foi fugindo dos revoltosos que os antepassados migraram e formaram a Comunidade de Palmeirinha.

Os poucos estudos acadêmicos e os sites e blogs que contam a história de Palmeirinha informam que, a partir dos relatos dos moradores mais antigos do lugar, os mesmos vieram da região de Parateca, no estado da Bahia - hoje também região de comunidades de remanescentes quilombolas - e da região dos garimpos de Grão Mogol e Diamantina. Informam ainda que esta comunidade ficou invisível por muito tempo, pois somente em 2006, em contato com estudiosos do Vale do São Francisco, foi que emergiu a discussão sobre o reconhecimento da comunidade como Remanescentes Quilombolas, porque a mesma, à época, apresentava características peculiares, como casa de barro com telha de palha, práticas cotidianas comunitárias de sobrevivência, uso comum da terra e manutenção da cultura.

Desse modo, de acordo com as considerações de Brandão (2012) sobre as comunidades tradicionais, em algum momento da história os "povoadores chegaram ali" (p. 353), nas sociedades indígenas "deuses ou seres naturais desde um lugar distante ou próximo geram seres humanos e fundaram 'ali' um lugar social” (BRANDÃO, 2012, p.353). A comunidade tradicional é um resultado de uma tensão entre as forças dominantes (capital) e o dominado, é um movimento de resistência daqueles que por motivos diversos, se organizaram em um determinado lugar por arbitrariedade de ações de modelos vigentes de dominação. A formação da sociedade indígena não perpassa esse viés, pois eles já estavam lá e foram retirados da terra onde sempre estiveram. Desta forma Brandão reafirma que a comunidade tradicional é o que está entre a sociedade indígena e a sociedade moderna.

A manutenção da cultura da Comunidade de Palmeirinha, inclusive no que diz respeito às práticas comunitárias de trabalho - em uma relação que Diegues (2001) chama de "harmônica" com a natureza - remete a uma especificidade do território quilombola na sua tradicionalidade, como destaca o autor em seus critérios para comunidade tradicional:

a)dependência e até simbiose com a natureza, os ciclos naturais e os recursos naturais renováveis a partir dos quais se constrói um modo de vida; 
SANTOS, L. M.; PEREIRA, A. M.; PAULA, A. M. N. R.

Comunidades remanescentes de quilombos: reflexão sobre territorialidades

b)conhecimento aprofundado da natureza e de seus ciclos que se reflete na elaboração de estratégias de uso e de manejo dos recursos naturais. Esse conhecimento é transferido de geração em geração por via oral;

c) noção de território ou espaço onde o grupo social se reproduz econômica e socialmente (...) (DIEGUES, 2001, p. 87).

Para Raffestin (1993), o espaço precede o território, pois entende que o território é um espaço modificado pela ação do homem, através das suas relações sociais, econômicas, políticas ou culturais.

(...) espaço e território não são termos equivalentes (...). É essencial compreender bem que o espaço é anterior ao território. O território se forma a partir do espaço, é o resultado de uma ação conduzida por um ator sintomático (ator que realiza um programa) em qualquer nível (...) Ao se apropriar de um espaço concreta ou abstratamente, o ator 'territorializa' o espaço (RAFFESTIN, 1993, 143).

Para Raffestin (1993) a ação do homem na natureza é um instrumento de poder. Enquanto esse autor define espaço como um recurso natural para o "desenvolver do território", Saquet (2010) compreende o espaço como elemento constituinte do território, pois não é possível dissociá-los, e ainda atribui valor de uso e troca para o espaço. Dessa forma “o processo de apropriação do território é econômico, político e cultural, no qual, a natureza exterior ao homem está presente e é influente, (...). O território é resultado e condição desta articulação e unidade" (SAQUET, 2007, p. 69). Partindo desses conceitos de território, podemos entender que as territorialidades se configuram a partir da vida cotidiana que reflete as relações sociais de poder e dominação que procedem no território (RAFFESTIN, 1993; SAQUET, 2007). Importante ressaltar ainda a concepção de Haesbaert sobre território, pois esse autor ressalta a dimensão das relações de poder e a correlação do território com a constituição identitária.

Podemos então afirmar que o território é, ao mesmo tempo, um recurso ou instrumento de poder e um valor (BONNEMAISON: CAMBREZY. 1996) - valor este que vai alem do simples valor de uso ou de troca, estendendo-se pela valorização simbólica, Identitário-existencial (HAESBAERT, 2003, p.15).

Segundo informações da Associação de Remanescentes Quilombolas de Palmeirinha, desde 2006, aos poucos, os moradores vêm resgatando sua história, buscando seus direitos e se organizando para fortalecimento dos seus modos de vida e do pertencimento ao lugar. É importante ressaltar que essa tradicionalidade se dá nos processos de fronteira e se afirma coletivamente e politicamente. A condição de comunidade remanescente de quilombo 
se constrói pela reação coletiva em busca do direito territorial, é uma produção política, na qual o grupo trilha um caminho para auto-afirmação que não se limita à descendência de escravos fugitivos (FIGUEIREDO, 2009). O reconhecimento da Comunidade de Palmeirinha traduz suas especificidades em um movimento de luta pela garantia do território e continuidade de um modo de vida particular.

A história da Comunidade Quilombola de Palmeirinha tem no século XXI o marco de visibilidade e consolidação de direitos parciais. Quanto às práticas universitárias de pesquisa, por hora tem parceria incipiente, pois ainda não houve estudos que possibilite saber sobre as perdas de terras que tiveram e as tensões na luta pelo território, pouco encontra é encontrado no remonte de sua história. Lima (2013), em seu estudo sobre inclusão digital, descreve que a partir de observação e entrevista com moradores, pôde acessar informações que expressam as características da comunidade como Remanescente de Quilombo, reconhecimento recentemente certificado.

A comunidade é formada por pessoas em sua grande maioria negra, parentes, descendentes dos primeiros ocupantes da comunidade, que supõem-se viverem há mais de 150 anos nessa terra que lhes provê o sustento e as condições básicas de sociabilidade. São em sua maioria católicos e exercem algumas formas de expressão particulares, tais como a dança de São Gonçalo, o batuque, as Pastorinhas e o Reisado, além de ofícios e ladainhas católicos ainda hoje cantadas em latim (LIMA, 2013, p. 4).

Saquet (2007) ainda aponta que a multidimensionalidade da territorialidade pode ser entendida pelas relações sociais, pelas apropriações do espaço geográfico (concreta ou simbólica), pela intencionalidade e com práticas espaço-temporais. A territorialidade tem caráter identitário, cultural, político e econômico e envolve as diferentes apropriações, interações e formação de classes sociais e de desigualdades.

Raffestin (1993) também destacada a multidimensionalidade para definir territorialidade em seu processo dinâmico e dialético que se objetiva no território.

(...) de acordo com nossa perspectiva, a territorialidade assume um valor bem particular, pois reflete o multidimensionamento do "vivido" territorial pelos membros de uma coletividade, pela sociedade em geral. Os homens "vivem" ao mesmo tempo, o processo territorial por intermédio de um sistema de relações existenciais e/ou produtivistas (RAFFESTIN, 1993, p. 158). 
SANTOS, L. M.; PEREIRA, A. M.; PAULA, A. M. N. R.

Comunidades remanescentes de quilombos: reflexão sobre territorialidades

O autor ainda destaca a dimensão das relações de poder na vida vivida, no cotidiano do território, assim a territorialidade se manifesta em todas as escala sociais. A territorialidade acontece no campo das relações, das vivências das várias faces do agir e do poder. Um estudo desenvolvido pela autora deste artigo juntamente com Boa, Moreira e Oliveira (2011), intitulado Vozes do Quilombo: um relato de experiência vivenciada na Comunidade Quilombola de Palmeirinha ${ }^{2}$, aponta que a Comunidade Quilombola de Palmeirinha teve sua certificação oficial como Comunidade Remanescente de Quilombo pela Fundação Cultural Palmares em 11/05/2011. Segundo o decreto ${ }^{\circ}{ }^{\circ} 4.887$, de 20 de novembro de 2003 Art. $2^{\text {o. }}$

Consideram-se remanescentes das comunidades dos quilombos, para os fins deste Decreto, os grupos étnico-raciais, segundo critérios de auto-atribuição, com trajetória histórica própria, dotados de relações territoriais específicas, com presunção de ancestralidade negra relacionada com a resistência à opressão histórica sofrida. $\S 1^{\circ}$ Para os fins deste Decreto, a caracterização dos remanescentes das comunidades dos quilombos será atestada mediante autodefinição da própria comunidade. $\S 2^{\circ}$ São terras ocupadas por remanescentes das comunidades dos quilombos as utilizadas para a garantia de sua reprodução física, social, econômica e cultural. $\S 3^{\circ}$ Para a medição e demarcação das terras, serão levados em consideração critérios de territorialidade indicados pelos remanescentes das comunidades dos quilombos, sendo facultado à comunidade interessada apresentar as peças técnicas para a instrução procedimental (...).

Esses mesmos autores constataram que a Comunidade Palmeirinha possuía em 2011 cerca de 60 famílias e aproximadamente 250 moradores que vivem da agricultura familiar e também da prestação de serviços braçais para propriedades privadas dos arredores e das cidades vizinhas, e possuem baixa escolaridade. Os moradores dessa comunidade compartilham a história de discriminação por serem negros, de luta pela manutenção da terra e migrações motivadas pela necessidade de sobrevivência.

\footnotetext{
${ }^{2}$ Artigo apresentado no II Seminário da Saúde da População Negra e Quilombola do Estado de Minas Gerais, I Fórum Estadual Sobre Saúde Bucal da População Negra e Quilombola de Minas Grais e também na $2^{a}$ Mostra Nacional de Práticas em Psicologia: compromisso com a construção do bem comum., O estudo teve como objetivo a análise dos resultados obtidos através de uma intervenção elaborada como ação integrante do Projeto de Extensão Universitário Cidadão, que partiu de uma proposta do Governo do Estado de Minas Gerais, através de uma parceria da Secretaria de Estado para o Desenvolvimento dos Vales Jequitinhonha, Mucuri e do Norte de Minas (Sedvan) e da Assessoria de Articulação, Parceria e Participação Social, da Governadoria com Instituições de Ensino Superior. O foco principal deste projeto foi a realização de ações em localidades com baixo índice de desenvolvimento humano. O nosso projeto consistia em utilizar a "contação" de histórias com o objetivo de resgate de memória do lugar. Os acadêmicos, juntamente com um professor/supervisor, interagiam com os moradores mais antigos e promoviam o encontro destes com os mais jovens, inclusive as crianças, para que contassem sobre a história da comunidade, dos antepassados, da ocupação, da cultura, com o intuído de resgatar a cultura local e a influência dos remanescentes de quilombolas no processo de formação da comunidade. Foram realizadas também oficinas com as crianças sobre os contos e mitos da comunidade.
} 
SANTOS, L. M.; PEREIRA, A. M.; PAULA, A. M. N. R.

Comunidades remanescentes de quilombos: reflexão sobre territorialidades

Sujeitos, grupos sociais, classes sociais não existem sem seus territórios. Este é o sentido supremo da luta pelos territórios dos povos camponeses e indígenas. $\mathrm{O}$ capitalismo sempre apropriou e ou subalternizou outras relações sociais e seus territórios. O desapossamento significa a intensificação da destruição dos territórios não subalternos e é exatamente neste ponto que destaco as formas de resistências que emergem dos campos, dos territórios rurais, muito mais que nas cidades. As disputas territoriais são diferentes no campo e na cidade. Nas cidades, os movimentos socioterritoriais lutam principalmente por moradias. Os locais de trabalho e de moradia na cidade e no campo são distintos. A propriedade camponesa reúne moradia e trabalho em um só território (FERNANDES, s/d p.13).

Nessa perspectiva apontada por Fernandes, compreendemos que os moradores da Comunidade de Palmeirinha possuem uma forte relação de pertencimento ao lugar, relatam que aquele território compõe as próprias existências e vice-versa (SANTOS et al, 2011), embora muitos tenham uma trajetória de ir e vir por conta da busca pelo trabalho. $\mathrm{O}$ reconhecimento como comunidade remanescente de quilombo, trouxe para os moradores uma nova perspectiva, principalmente para estreitarem os laços dos mais jovens com as práticas comunitárias. Toda essa vivência, toda a dinâmica de acontecimentos do dia a dia na territorialização da comunidade de Palmeirinha, diz do seu processo de territorialidade.

No território, há temporalidades e territorialidades, descontinuidades; múltiplas variáveis, determinações e relações recíprocas e unidade. É espaço de vida, objetiva e subjetivamente; significa chão, formas espaciais, relações sociais, natureza exterior ao homem; obras e conteúdos. É produto e condição de ações históricas e multiescalares, com desigualdades, diferenças, ritmos e identidade(s). O território é processual e relacional, (i)material (SAQUET, 2007, p. 73).

O território é incorporado na dimensão identitária da comunidade, pois todos os processos materiais e imateriais da vida cotidiana acontecem no território e também a partir dele, configurando assim a territorialidade.

\section{CONSIDERAÇÕES FINAIS}

Esta breve discussão nos permitiu apreender sobre o histórico de formação dos quilombos no Brasil, bem como no Norte de Minas Gerais. Entendemos que as várias abordagens que envolvem o conceito de Comunidade Tradicional abarcam as características e condições dos remanescentes de quilombo. Quanto às diversas concepções de território e territorialidade compreendemos que o primeiro se constitui em uma produção histórica, relacional material e imaterial e que o segundo trata da dimensão vivencial, ou seja, do campo 
subjetivo da territorialização. Assim, a Comunidade Quilombola de Palmeirinha, em sua condição de Comunidade Tradicional, produz na sua trajetória a territorialidade.

As considerações aqui apresentadas não pretendem esgotar a discussão sobre o processo de territorialidade das Comunidades de Remanescentes de Quilombos e, menos ainda, dar por encerrado a investigação sobre a Comunidade de Remanescentes Quilombolas de Palmeirinha. Pelo contrário, as discussões apresentadas neste artigo nos remetem à necessidade de ampliarmos as investigações sobre as territorialidades desta comunidade, no que tange seus processos políticos, jurídicos e de manutenção da cultura.

\section{REFERÊNCIAS}

ARAUJO, Elisa De Cotta. Nas margens do São Francisco: sociodinâmicas ambientais, expropriação territorial e afirmação étnica do Quilombo da Lapinha e dos vazanteirosdo Pau de Légua (Dissertação de Mestrado) - PPGDS -Unimontes, Montes Claros, 2009.

BRANDÃO, Carlos Rodrigues. A Comunidade Tradicional.In: COSTA, João B. A; OLIVEIRA, Claudia L. Cerrado, Gerais, Sertão: Comunidades Tradicionais nos sertões roseanos. São Paulo: Intermeios, 2012.

BRASIL. Constituição (1988). Constituição: República Federativa do Brasil. Brasília: Senado Federal, 1988.

COSTA, João Batista de Almeida. Do Tempo da Fatura dos Crioulos ao Tempo de Penúria dos Morenos: Identidade através de rito em Brejo dos Crioulos (MG). (Dissertação de Mestrado) Brasília: UnB/Departamento de Antropologia, 1999.

COSTA FILHO, Aderval. Os Gurutubanos: territorialização, produção e sociabilidade em um quilombo do centro norte-mineiro. Tese (Doutorado) - Instituto de Ciências Sociais - Departamento de Antropologia da UNB.. Brasília: ICS-UnB, 2008.

DIEGUES, Antônio Carlos Santana. O Mito da Natureza Intocada. 3 ed.São Paulo: Hucitec, 2001.

FERNANDES, Bernardo Mançano. Sobre a Tipologia de Territórios. Disponível em http://www.gepec.ufscar.br/textos-1/textos-educacao-do-campo/sobre-a-tipologia-deterritorios/view acesso em set de 2015.

FIGUEIREDO, André Luiz Videira de. O “caminho quilombola": interpretação constitucional e reconhecimento de direitos étnicos. Tese (Doutorado) - Instituto Universitário de Pesquisas do Rio de Janeiro. Rio de Janeiro: UCAM/IUPERJ, 2009. 
INSTITUTO Brasileiro de Geografia e Estatística -IBGE. Censo Demográfico de Pedra de Maria da Cruz - Minas Gerais. 2010. Disponível em

<http://cidades.ibge.gov.br/xtras/perfil.php?codmun=314915 > acesso em dez. de 2015.

HAESBAERT, Rogério. Da Desterritorialização à Multiterritorialidade. Boletim Gaúcho de Geografia, 29: 11-24, jan., 2003. Versão online disponível em

<http://seer.ufrgs.br/bgg/article/view/38739/26249> acesso em 05 de jan. 2016.

Dos Múltiplos Territórios à Multiterritorialidade. 2004. Disponível em <http://www.ufrgs.br/petgea/Artigo/rh.pdf> acesso em 06 de jun. 2016.

LEITE, Ilka Boaventura. Os Quilombos no Brasil: questões conceituais e normativas. Etnográfica, Vol. IV (2), 2000, pp. 333-354. Disponível em

<http://ceas.iscte.pt/etnografica/docs/vol_04/N2/Vol_iv_N2_333-354.pdf $>$ acesso em $18 \mathrm{de}$ out. 2015.

LIMA, Hélder Seixas. Inclusão Digital em uma Comunidade Quilombola no Norte de Minas: um novo olhar sobre a globalização e o domínio da técnica. $2^{\circ}$ Seminário Nacional de Inclusão Digital - SENID. Passo Fundo/RS, 08-10 de abril, 2013. Disponível em <http://gepid.upf.br/senid/download/senid2013/Artigo_Completo/109637.pdf> acesso em 16 de out. 2015

LITTLE, Paul E. Territórios Sociais e Povos Tradicionais no Brasil: Por uma antropologia da territorialidade. Série Antropologia, Departamento de Antropologia Instituto de Ciências Sociais Universidade de Brasília, 2002.

MARÉS, Carlos. Introdução: terras de preto. In: Leitão, S. (Org.). Direitos territoriais das comunidades negras rurais. São Paulo, Doc. ISA n05, 1999.

QUERINO, Augusto José. A Liberdade e os Quilombos na Ocupação Humana do Território no Sertão Norte Mineiro. Revista Desenvolvimento Social - Universidade Estadual de Montes Claros - MG, 2006. Disponível em <http://www.rds.unimontes.br/index.php/desenv_social/article/view/77> acesso em 16 de out. de 2015.

RAFFESTIN, Claude. Por uma geografia do poder. São Paulo: Ática, 1993.

REIS, João José. Quilombos e Revoltas Escravas no Brasil. Revista U S P, São Paulo ( 28 ) : 14 - 3 9, dezembro/fevereiro, 1995 / 9 6. Disponível em <http://www.usp.br/revistausp/28/02-jreis.pdf> acesso em 15 de out. de 2015.

SAQUET, Marcos Aurélio. As Diferentes Abordagens do Território e a Apreensão do Movimento e da (I)Materialidade. Geosul, Florianópolis, v.22. n. 43, p 55-76, jan./jun. 2007.

SANTOS, Lilian Maria et al. Vozes do Quilombo: um relato de experiência vivenciada na Comunidade Quilombola de Palmeirinha. $2^{\text {a }}$ Mostra Nacional de Práticas em Psicologia: compromisso com a construção do bem comum. São Paulo, SP, 2012. 
SANTOS, Lilian Maria et al. Vozes do Quilombo: um relato de experiência vivenciada na Comunidade Quilombola de Palmeirinha. II Seminário da Saúde da População Negra e Quilombola do Estado de Minas Gerais, I Fórum Estadual Sobre Saúde Bucal da População Negra e Quilombola de Minas Grais, Montes Claros, Mg, 2011.

Autoras

Lilian Maria Santos - Possui Graduação em Psicologia pela Universidade Federal de São João Del-Rei (UFSJ) e Mestrado em Desenvolvimento Social pela Universidade Estadual de Montes Claros (UNIMONTES). Atualmente é Doutoranda do Programa de Pós-Graduação em Desenvolvimento Social da Universidade Estadual de Montes Claros (UNIMONTES).

Anete Marília Pereira - Possui Graduação em Geografia pela Universidade Estadual de Montes Claros (UNIMONTES), Mestrado em Geografia pela Universidade Federal de Minas Gerais (UFMG) e Doutorado em Geografia pela Universidade Federal de Uberlândia (UFU). Atualmente é Professora do Programa de Pós-Graduação em Geografia do Departamento de Geociências e do Programa de Pós-Graduação em Desenvolvimento Social, ambos da Universidade Estadual de Montes Claros (UNIMONTES).

Andréa Maria Narciso Rocha de Paula - Possui Graduação em Ciências Sociais pela Universidade Estadual de Montes Claros (UNIMONTES), Mestrado e Doutorado em Geografia, ambos cursados pela Universidade Federal de Uberlândia (UFU). Atualmente é Professora do Programa de Pós-Graduação em Desenvolvimento Social e do Departamento de Política e Ciências Sociais da Universidade Estadual de Montes Claros (UNIMONTES).

Artigo recebido em: 15 de setembro de 2016.

Artigo aceito em: 26 de abril de 2017.

Artigo publicado em: 30 de junho de 2018. 